\title{
Remarkable Anti-Trichomonas vaginalis Activity of Plants Traditionally Used by the Mbyá-Guarani Indigenous Group in Brazil
}

\author{
Clara Lia Costa Brandelli, ${ }^{1}$ Patrícia de Brum Vieira, ${ }^{1}$ \\ Alexandre José Macedo, ${ }^{2}$ and Tiana Tasca ${ }^{1}$ \\ ${ }^{1}$ Faculdade de Farmácia, Universidade Federal do Rio Grande do Sul, Avenida Ipiranga 2752, 90610-000 Porto Alegre, RS, Brazil \\ ${ }^{2}$ Faculdade de Farmácia e Centro de Biotecnologia, Universidade Federal do Rio Grande do Sul, Avenida Ipiranga 2752, \\ 90610-000 Porto Alegre, RS, Brazil \\ Correspondence should be addressed to Tiana Tasca; tiana.tasca@ufrgs.br
}

Received 16 April 2013; Accepted 4 June 2013

Academic Editor: Abhay R. Satoskar

Copyright () 2013 Clara Lia Costa Brandelli et al. This is an open access article distributed under the Creative Commons Attribution License, which permits unrestricted use, distribution, and reproduction in any medium, provided the original work is properly cited.

\begin{abstract}
Trichomonas vaginalis, a flagellate protozoan, is the causative agent of trichomonosis, the most common nonviral sexually transmitted disease worldwide. Taking into account the increased prevalence of metronidazole-resistant isolates, alternative drugs are essential for the successful treatment. Natural products are the source of most new drugs, and popular wisdom about the use of medicinal plants is a powerful tool in this search. In this study, the activity of 10 medicinal plants extensively used in daily life by Mbyá-Guarani indigenous group was evaluated against seven different T. vaginalis isolates. Among the aqueous extracts tested, Verbena sp. (Guachu ka’a in Mbyá-Guarani language) and Campomanesia xanthocarpa (Guavira in Mbyá-Guarani language) showed the highest activity against T. vaginalis with MIC value of $4.0 \mathrm{mg} / \mathrm{mL}$ reaching $100 \%$ of efficacy against the parasite. The kinetic growth assays showed that the extracts promoted complete growth abolishment after $4 \mathrm{~h}$ of incubation. In addition, the extracts tested did not promote a significant hemolytic activity against human erythrocytes. Our results show for the first time the potential activity of Verbena sp. and C. xanthocarpa against T. vaginalis. In addition, this study demonstrates that indigenous knowledge is an important source of new prototype antiprotozoal agents.
\end{abstract}

\section{Introduction}

Trichomonas vaginalis parasitizes the urogenital human tract causing trichomonosis, the most prevalent non-viral sexually transmitted disease worldwide, being responsible for 248 million new cases annually [1]. After colonization, the parasite causes vaginitis, urethritis, and prostatitis [2]. Moreover, the pathogen has been associated with serious consequences as adverse pregnancy outcomes and preterm birth [3], infertility [4], predisposition to cervical cancer [5], and pelvic inflammatory disease [6]. Importantly, trichomonosis acts as a cofactor in human immunodeficiency virus (HIV) transmission and acquisition $[7,8]$. In spite of impact of this infection, the therapeutic arsenal is restricting, and only metronidazole and tinidazole, both 5-nitroimidazole drugs, are approved by the FDA for trichomonosis treatment [9]. Although the cure rate is high, treatment failure can be observed and the resistance of T. vaginalis isolates is the main reason of treatment failure [10]. In this sense, it is undoubtedly necessary that the investigation for new alternatives for the treatment of trichomonosis and two strategies can be followed: (i) the search for new therapeutic targets, which is essential to rational development of new antiparasitic agents and (ii) the investigation of new anti- $T$. vaginalis compounds structurally distinct from 5-nitroimidazoles and, consequently, acting by different mechanism as demonstrated by our group $[11,12]$.

In this context, natural products, especially medicinal plants, are immeasurable as a potent source of bioactive molecules. Since ancient times, people use plants to treat common infectious diseases, and some of these traditional 
medicines are still integrated as part of the cure of diverse pathologies [13]. In addition, the search based on ethnopharmacological information rescues the immense empirical knowledge of plants utilization [14, 15]. In this context, regarding natural environment and vast wealth of genetic resources, Brazil is a country of great interest to ethnopharmacology [16].

Indigenous people have a wealth of biodiversity information and know how to capture and use natural resources [17]. Despite of the fact that several drugs have been discovered through traditional cures and folk knowledge, in Brazil there are 122 indigenous ethnic groups, but only $30 \%$ of them were investigated with regard to ethnobotanical aspects $[18,19]$. Therefore, the study of plants used by indigenous medicine is important to interconnect traditional medicine and biotic environment preserving the indigenous ancient knowledge.

Parasitic protozoa remain a major threat to human and animal health, and there are few effective drugs for the treatment of many protozoal diseases. Taking into account the indigenous ethnopharmacology as a contributor to the systematic screening of plants with antiprotozoal activity, this study evaluated the anti- $T$. vaginalis activity of the most important medicinal plants used in Mbyá-Guarani indigenous medicine located in South of Brazil.

\section{Materials and Methods}

2.1. Parasite Culture Conditions. In this study, seven isolates of T. vaginalis were used: 30236 and 30238 from American Type Culture Collection (ATCC); TV-LACM1, TV-LACM2, and TV-LACM3 (fresh clinical isolates from female patients); TV-LACH1 and TV-LACH2 (fresh clinical isolates from male patients) all from Laboratório de Análises Clínicas e Toxicológicas, Faculdade de Farmácia, UFRGS, Brazil (project with ethical approval by UFRGS Ethical Research Committee, number 18923). Trichomonads were axenically cultured in trypticase-yeast extract-maltose (TYM) medium ( $\mathrm{pH}$ 6.0), supplemented with $10 \%$ heat-inactivated bovine serum and incubated at $37^{\circ} \mathrm{C}[20]$.

2.2. Plant Material. Plant material was collected from indigenous tribe Mbyá-Guarani located at the Lomba do Pinheiro, Porto Alegre, RS, Brazil $\left(30^{\circ} 06^{\prime} 47.62^{\prime \prime} \mathrm{S}\right.$ and $\left.51^{\circ} 07^{\prime} 37.85^{\prime \prime} \mathrm{W}\right)$, in March 2011. This village is denominated Tekoá Anhetenguá (in English, True Village), and 200 people live in the area gathered at 40 families. The women of the village have the knowledge of medicinal plants used by the entire population and conducted the collection of specimens. Ten plants routinely used in indigenous medicine for infectious diseases were collected: leaves of Aloe arborescens Mill. (ICN 173371), aerial parts of Bidens pilosa L. (ICN 167397), aerial parts of Rhipsalis baccifera (ICN 167402), barks of Luehea divaricata (ICN 167403), roots of Trichilia sp. (ICN 173126), leaves of Campomanesia xanthocarpa O. Berg. (ICN 167401), leaves of Coix lacryma-jobi Lin. (ICN 167396), leaves of Citrus limonium (ICN 167399), leaves of Citrus reticulata (ICN 173127), and leaves of Verbena sp. (ICN 167394). The voucher specimens were deposited at the herbarium of the Universidade Federal do Rio Grande do Sul (ICN).
2.3. Preparation of Plant Extracts. The fresh plants extracts were prepared conforming traditional use by indigenous people by decoction at $60^{\circ} \mathrm{C}$ for $60 \min [1: 10 ;(\mathrm{w}: \mathrm{v})]$. Aqueous extracts were freeze dried, and the work solution was prepared at $8.0 \mathrm{mg} / \mathrm{mL}$ in ultrapure water, sterilized by filtration $(0.22 \mu \mathrm{m})$ and stored at $-20^{\circ} \mathrm{C}$.

2.4. Anti-Trichomonas vaginalis Assay. Ten aqueous extracts were screened in vitro for activity against $T$. vaginalis. The assay was performed in 96 microtiter plates at final concentration of $4.0 \mathrm{mg} / \mathrm{mL}$ in the wells. The inhibitory minimum concentration (MIC) was determined using an eightfold dilution $(4.0-0.031 \mathrm{mg} / \mathrm{mL})$, and the viability of the trophozoites was determined according to a fluorimetric method [21]. Two controls were performed: negative control only with trophozoites and a positive control with $8.0 \mu \mathrm{M}$ metronidazole (Sigma Chemical Co., St. Louis, MO, USA). The experiments were performed at least in three independent experiments, in triplicate. The results were expressed as the percentage of viable trophozoites compared to untreated parasites.

2.5. Growth Effect of Aqueous Extracts. In order to investigate the effect of the active aqueous extracts on $T$. vaginalis growth, a kinetic growth curve was performed using the ATCC 30236 isolate. The parasites initial density of $2.0 \times$ $10^{5}$ trophozoites $/ \mathrm{mL}$ was incubated with the extracts at MIC value in TYM medium. The trophozoites were counted using a hemocytometer during $72 \mathrm{~h}$. The results were expressed as trophozoite number $\left(10^{5} / \mathrm{mL}\right)$. For microscopic analysis, the controls and treated parasites were centrifuged for $10 \mathrm{~min}$ at $2,000 \mathrm{rpm}$ to concentrate the organisms after $4 \mathrm{~h}$ of incubation, and the preparation was observed in light microscope (magnified $\times 1,000$ ) by trypan blue dye exclusion.

2.6. Hemolytic Assay. This assay was performed according to the method used by Rocha et al. [22]. Blood type O positive from healthy human volunteers was collected with Alsever's solution $(1: 1)$ and centrifuged at $2,000 \mathrm{rpm}$ for $5 \mathrm{~min}$. The erythrocyte fraction was washed three times with PBS $1 \mathrm{x}(\mathrm{pH}$ 7.0) and resuspended to give $1 \%$ red cell suspension (v/v). Aqueous extracts concentrations were chosen according to minimum inhibitory concentration (MIC) determined in the susceptibility assay. The erythrocytes were incubated with the extracts at $37^{\circ} \mathrm{C}$ under agitation for $1 \mathrm{~h}$ and then were centrifuged at 3,000 rpm for $5 \mathrm{~min}$. The absorbance of the supernatant was measured at $540 \mathrm{~nm}$. The experiment was performed in triplicate, and the percentage of hemolysis caused by each sample tested was calculated in comparison to $100 \%$ hemolytic activity of saponin from Quillaja saponaria [23].

\section{Results and Discussion}

This study evaluated the anti-T. vaginalis activity of aqueous extracts of 10 medicinal plants used in medicine system Mbyá-Guarani. Importantly, among the plants tested, we found two aqueous extracts with a potent anti-T. vaginalis in vitro activity. The promising extracts are of Verbena sp. and Campomanesia xanthocarpa. The extract from Verbena sp., 


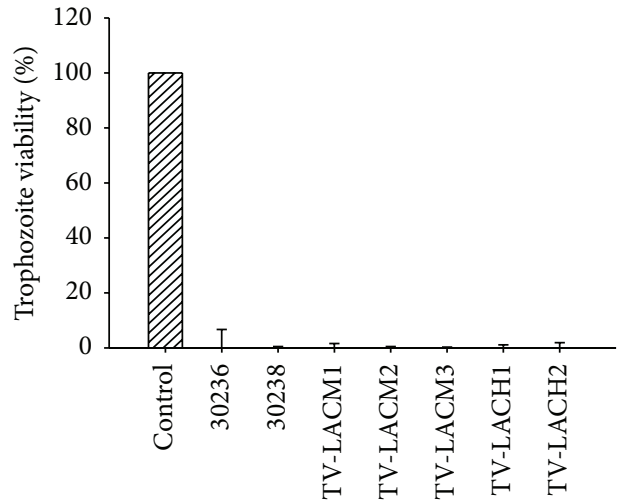

(a)

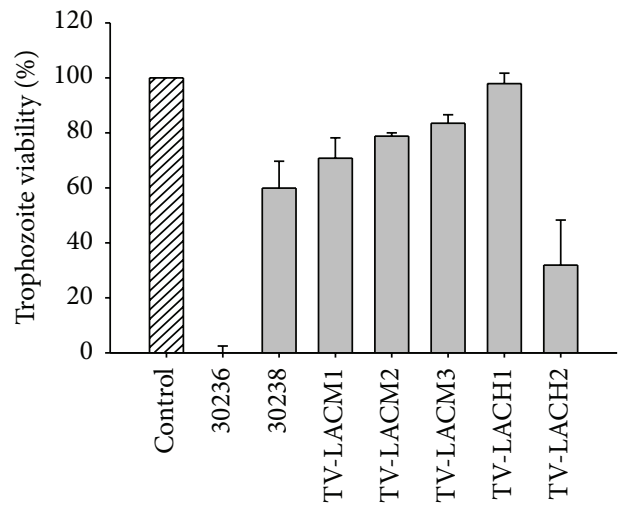

(c)

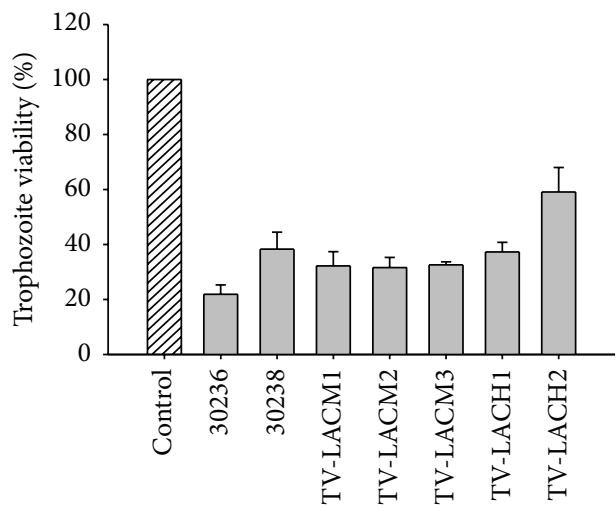

(e)

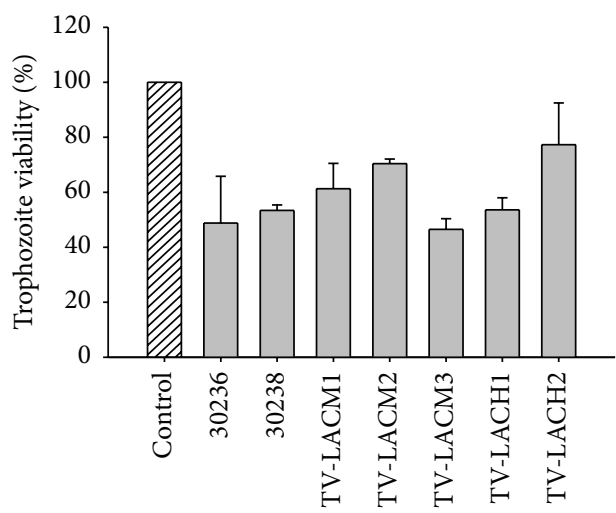

(g)

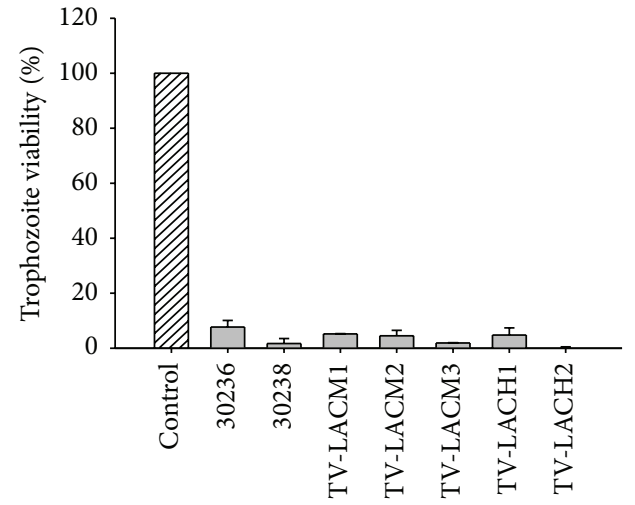

(b)

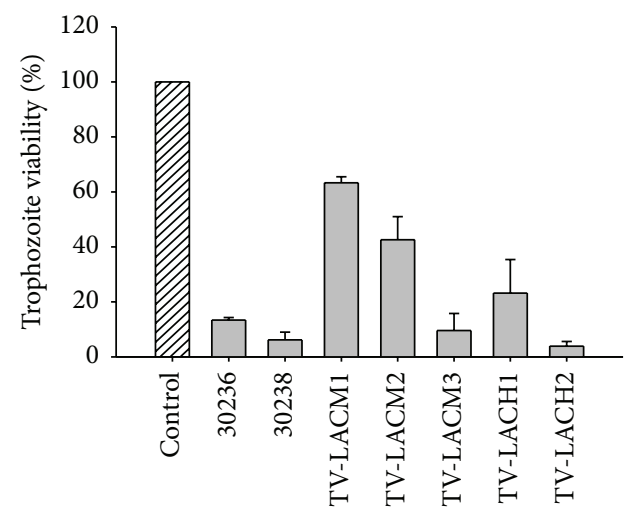

(d)

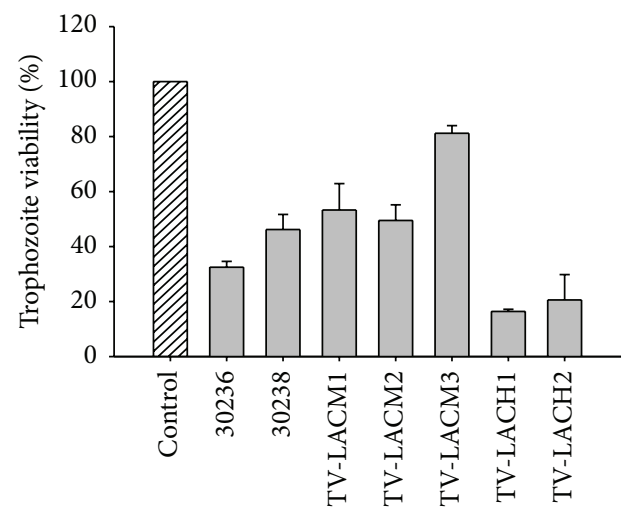

(f)

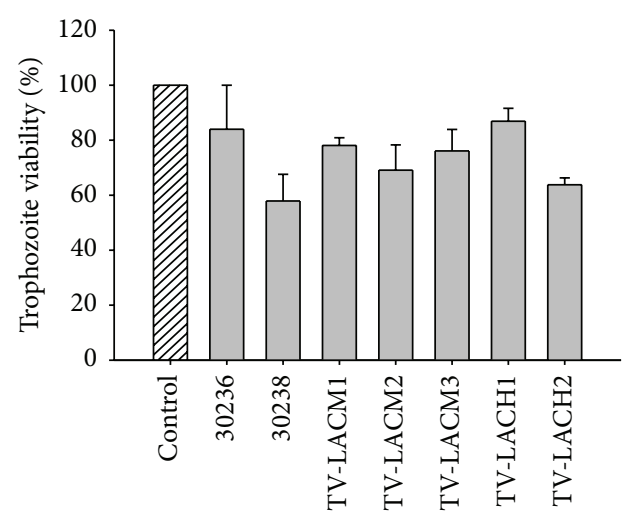

(h)

Figure 1: Continued. 


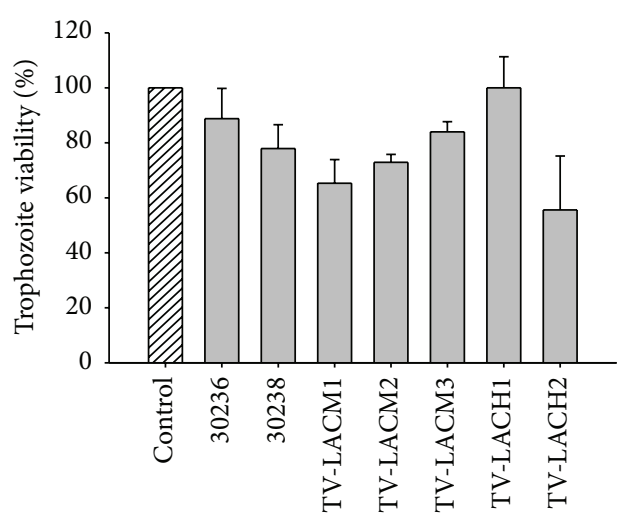

(i)

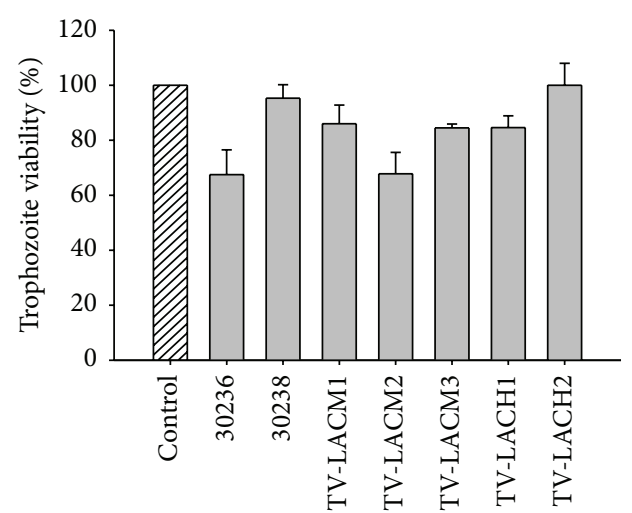

(j)

Figure 1: Effect of selected Mbyá-Guarani medicinal plants at $4.0 \mathrm{mg} / \mathrm{mL}$ on different Trichomonas vaginalis isolates. (a) Verbena sp. (b) Campomanesia xanthocarpa. (c) Bidens pilosa. (d) Luehea divaricata. (e) Coix lacryma-jobi. (f) Trichilia sp. (g) Citrus limonium. (h) Aloe arborescens. (i) Citrus reticulata. (j) Rhipsalis baccifera. Data represent means \pm standard deviation.

TABLE 1: Hemolytic activity of the aqueous extracts that showed the best anti-Trichomonas vaginalis activity and respective MIC determined by susceptibility assay.

\begin{tabular}{lcc}
\hline & \multicolumn{2}{c}{ Aqueous extract } \\
& Verbena sp. & Campomanesia xanthocarpa \\
\hline MIC $(\mathrm{mg} / \mathrm{mL})$ & 4.0 & 4.0 \\
Hemolysis $(\%) \pm$ S.D. & $6.5 \pm 0.02$ & $7.6 \pm 0.01$ \\
\hline
\end{tabular}

at $4.0 \mathrm{mg} / \mathrm{mL}$, demonstrated the optimal anti-T. vaginalis activity inducing complete cytotoxicity (100\% of parasites death) upon all distinct trichomonads isolates (Figure 1(a)). The leaves extract of Campomanesia xanthocarpa at the same concentration also showed a very high anti-T. vaginalis activity, reducing the parasite viability up to $96 \%$ (Figure 1(b)).

Other aqueous extracts displayed a variety of results. The aqueous extract obtained from Bidens pilosa totally abolished the trophozoites viability only of the 30236 isolate (Figure 1(c)). The extract of the barks of Luehea divaricata induced a reduction of $T$. vaginalis viability differently in each trichomonads isolate tested (Figure 1(d)). The leaves of Coix lacryma-jobi induced, on average, $75 \%$ of viability reduction on $T$. vaginalis isolates; however, for the TV-LACH2 isolate, the reduction was only $40 \%$ (Figure $1(\mathrm{e})$ ). The fresh clinical isolates from male patients (TV-LACH1 and TV-LACH2) presented higher susceptibility than the isolates from female patients (ATCC and fresh clinical) when the root extract of Trichilia sp. was tested (Figure 1(f)). Extracts of leaves from Citrus limonium reduced about $40 \%$ the viability of isolates (Figure 1(g)). The extracts from Aloe arborescens and Citrus reticulata decreased the viability of $50 \%$ of at least one isolate (Figures 1(h) and 1(i)), while Rhipsalis baccifera reduced only $30 \%$ the viability of 30236 and TV-LACM2 isolates (Figure 1(j)).

In comparison to the other extracts, the extracts from Verbena sp. and C. xanthocarpa demonstrated the most promising activity against $T$. vaginalis, and the minimum inhibitory concentration was determined for the 30236 isolate (Table 1).

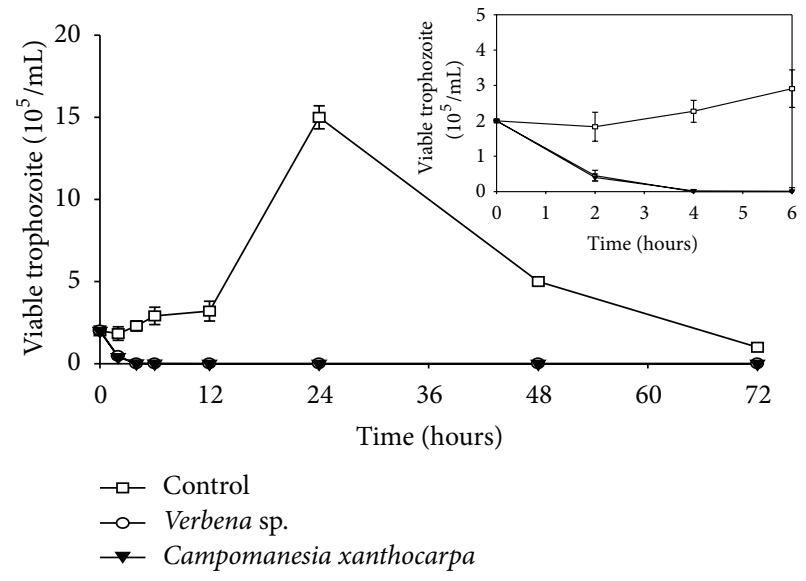

FIGURE 2: Kinetic growth curve of Trichomonas vaginalis 30236 isolate after treatment with aqueous extracts of Verbena sp. and Campomanesia xanthocarpa at $4.0 \mathrm{mg} / \mathrm{mL}$. The trophozoites growth was completely inhibited by the extracts in 4 hours of incubation. Data represent means \pm standard deviation of at least three experiments, all in triplicate.

In order to investigate the effect of the most active extract on parasite growth and viability, a kinetic growth curve was performed. The control exhibited the classical growth peak after $24 \mathrm{~h}$ of incubation; however, the organisms treated with extracts of Verbena sp. and C. xanthocarpa, after $4 \mathrm{~h}$ of incubation, evoked a complete growth abolishment (Figure 2) and showed a characteristic blue color by trypan blue dye exclusion indicating cell death (Figure 3 ).

In order to investigate a possible effect of the C. xanthocarpa and Verbena sp. extracts on parasites membrane and also to have preliminary data on cytotoxicity against mammalian cells, hemolytic activity of these extracts was conducted. The Verbena sp. and C. xanthocarpa extracts were tested at MIC values and demonstrated 6.5 and $7.6 \%$ erythrocytes lysis, respectively (Table 1). These results demonstrated that both extracts, at MIC values, did not promote a significant hemolytic activity, indicating that the mechanism of 


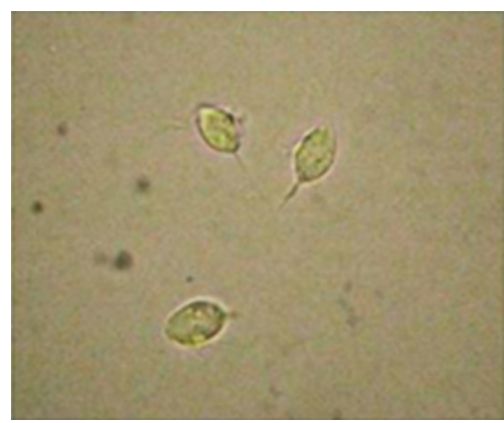

(a) Control

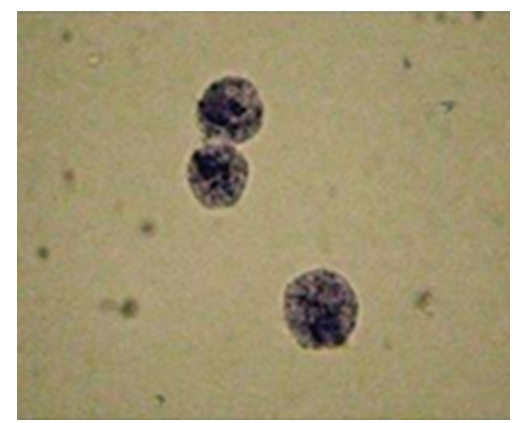

(b) Verbena sp.

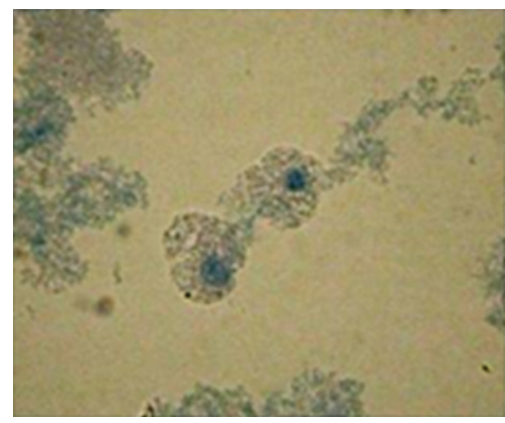

(c) Campomanesia xanthocarpa

FIgURE 3: Microscopic analysis of parasites morphology in light microscope (magnified $\times 1,000$ ) by trypan blue dye exclusion. (a) Control; (b) after 4 hours of treatment with aqueous extract of Verbena sp.; (c) after 4 hours of treatment with aqueous extract of Campomanesia xanthocarpa.

action responsible for the parasite viability reduction probably does not involve parasitic membrane disruption. Moreover and importantly, these findings suggest that both extracts are not toxic to mammalian cells, since they did not lyse human erythrocytes.

This study contributes to rescue the indigenous knowledge about medicinal plants. The indigenous Mbyá-Guarani use Verbena sp. (Guachu ka'a in Mbyá-Guarani language), as tea, for relief of symptoms of infectious diseases, such as fever. This is in agreement of the literature that relates Verbena sp. infusion as sedative, analgesic to inflammatory disorders, skin burns, amenorrhea, depression, and gastric diseases [2426]. Moreover, this species has a variety of chemical constituents, as flavonoid, iridoid glycosides, phenylpropanoid glycoside, sterols, triterpenes, and glycoconjugate, and the biological activity may be partially attributed to them [24]. In addition, this tribe utilizes the leaves of C. xanthocarpa (Guavira in Mbyá-Guarani language) for treatment of diarrhea, stomach pain, and worms. This plant is traditionally used in the south of Brazil as depurative, antidiarrhoeic, cleanser, and antirheumatic, and to decrease the blood cholesterol [27], and these properties may be attributed to tannins, saponins, and flavonoids (quercetin, myricetin, quercitrin, and rutin), compounds present in the leaves of $C$. xanthocarpa [28].

The rescue ethnopharmacology of historical uses of plants is recognized as valuable for bioprospection, since they afford the rationale for selection and research of medicinal plants [15]. This study describes the first report on the antiprotozoal activity of Verbena sp. and C. xanthocarpa. In addition, other species of the families Verbenaceae and Myrtaceae were tested against T. vaginalis, however, without success $[29,30]$. Several biodiversities and traditional knowledge of different populations have guided studies to search new prototypes anti-T. vaginalis. Recently, the potential of plants traditionally used from Caatinga against T. vaginalis was reported [31]. Calzada et al. [29] demonstrated that plants used for urogenital tract disorders in Mexican traditional medicine showed effect against this protozoan. Amaryllidaceae species used against venereal diseases in South Africa also showed promising activity against $T$. vaginalis $[11,32]$.

Considering the impact of trichomonosis in public health and the emergent number of resistant T. vaginalis isolates, it is necessary alternatives for the treatment of this infection. Natural products are a promising source of active molecules, and the ethnopharmacology approach rescues the knowledge of population of medicinal plants. This wisdom combined with chemical and pharmacological studies presents a precious value in the bioprospection of innovates, safe, and accessible drugs. This pioneer study demonstrated relevant results about anti-T. vaginalis activity of the Verbena sp. and C. xanthocarpa, plants traditionally used by indigenous population Mbyá-Guarani for infectious diseases. Despite of showing strong anti-T. vaginalis activity, this report rescued the knowledge of indigenous people, avoiding the miscarriage of this wisdom.

\section{Authors' Contribution}

Clara Lia Costa Brandelli and Patrícia de Brum Vieira contributed equally to this work. 


\section{Acknowledgments}

This work was supported by the NANOBIOTEC-Brazil program from CAPES and FAPERGS. The authors thank Chieftain José Cirilo Pires Morinico (tribe Mbyá-Guarani), for making possible the accomplishment of this study and for the valuable information. Alexandre José Macedo and Tiana Tasca thank CNPq for researcher fellowships.

\section{References}

[1] WHO, Global Incidence and Prevalence of Selected Curable Sexually Transmitted Infections-2008, World Health Organization, Geneva, Switzerland, 2012, http://apps.who.int/iris/bitstream/ 10665/75181/1/9789241503839_eng.pdf.

[2] D. Petrin, K. Delgaty, R. Bhatt, and G. Garber, "Clinical and microbiological aspects of Trichomonas vaginalis," Clinical Microbiology Reviews, vol. 11, no. 2, pp. 300-317, 1998.

[3] M. A. Klebanoff, J. C. Carey, J. C. Hauth et al., "Failure of metronidazole to prevent preterm delivery among pregnant women with asymptomatic Trichomonas vaginalis infection," The New England Journal of Medicine, vol. 345, no. 7, pp. 487-493, 2001.

[4] F. Grodstein, M. B. Goldman, and D. W. Cramer, "Relation of tubal infertility to history of sexually transmitted diseases," American Journal of Epidemiology, vol. 137, no. 5, pp. 577-584, 1993.

[5] M. Viikki, E. Pukkala, P. Nieminen, and M. Hakama, "Gynaecological infections as risk determinants of subsequent cervical neoplasia," Acta Oncologica, vol. 39, no. 1, pp. 71-75, 2000.

[6] T. L. Cherpes, H. C. Wiesenfeld, M. A. Melan et al., "The associations between pelvic inflammatory disease, Trichomonas vaginalis infection, and positive herpes simplex virus type 2 serology," Sexually Transmitted Diseases, vol. 33, no. 12, pp. 747$752,2006$.

[7] F. Sorvillo, L. Smith, P. Kerndt, and L. Ash, "Trichomonas vaginalis, HIV, and African-Americans," Emerging Infectious Diseases, vol. 7, no. 6, pp. 927-932, 2001.

[8] B. van der Pol, C. Kwok, B. Pierre-Louis et al., "Trichomonas vaginalis infection and human immunodeficiency virus acquisition in African women," Journal of Infectious Diseases, vol. 197, no. 4, pp. 548-554, 2008.

[9] V. Ali and T. Nozaki, "Current therapeutics, their problems, and sulfur-containing-amino-acid metabolism as a novel target against infections by "amitochondriate" protozoan parasites," Clinical Microbiology Reviews, vol. 20, no. 1, pp. 164-187, 2007.

[10] J. R. Schwebke and F. J. Barrientes, "Prevalence of Trichomonas vaginalis isolates with resistance to metronidazole and tinidazole," Antimicrobial Agents and Chemotherapy, vol. 50, no. 12, pp. 4209-4210, 2006.

[11] R. B. Giordani, P. B. Vieira, M. Weizenmann et al., "Candimineinduced cell death of the amitochondriate parasite Trichomonas vaginalis," Journal of Natural Products, vol. 73, no. 12, pp. 20192023, 2010.

[12] R. B. Giordani, P. B. Vieira, M. Weizenmann et al., "Lycorine induces cell death in the amitochondriate parasite, Trichomonas vaginalis, via an alternative non-apoptotic death pathway," Phytochemistry, vol. 72, no. 7, pp. 645-650, 2011.

[13] J. L. Ríos and M. C. Recio, "Medicinal plants and antimicrobial activity," Journal of Ethnopharmacology, vol. 100, no. 1-2, pp. 8084, 2005.
[14] M. Heinrich, "Ethnobotany and natural products: the search for new molecules, new treatments of old diseases or a better understanding of indigenous cultures?" Current Topics in Medicinal Chemistry, vol. 3, no. 2, pp. 141-154, 2003.

[15] C. L. C. Brandelli, R. B. Giordani, A. J. Macedo, G. A. de Carli, and T. Tasca, "Indigenous traditional medicine: plants for the treatment of diarrhea," in Nature Helps...: How Plants and Other Organisms Contribute to Solve Health Problems, pp. 1-18, Springer, Berlin, Germany, 1st edition, 2011.

[16] E. Elisabetsky and L. Wannmacher, "The status of ethnopharmacology in Brazil," Journal of Ethnopharmacology, vol. 38, no. 2-3, pp. 137-143, 1993.

[17] F. L. H. Rego, A. J. Brand, and R. B. Costa, "Genetic resources, biodiversity, traditional knowledge Guarani Kaiowá and local development," Interações, vol. 11, no. 1, pp. 55-69, 2010.

[18] D. F. Coutinho, L. M. A. Travassos, and F. M. M. Amaral, "Estudo etnobotânico de plantas medicinais utilizadas em comunidades indígenas no estado do Maranhão-Brasil," Visão Acadêmica, vol. 3, no. 1, pp. 7-12, 2002.

[19] A. H. Gilani and A.-U. Rahman, "Trends in ethnopharmacology," Journal of Ethnopharmacology, vol. 100, no. 1-2, pp. 43-49, 2005.

[20] L. S. Diamond, "The establishment of various Trichomonas of animals and man in axenic cultures," The Journal of Parasitology, vol. 43, no. 4, pp. 488-490, 1957.

[21] M. Duarte, R. B. Giordani, G. A. de Carli, J. A. Zuanazzi, A. J. Macedo, and T. Tasca, "A quantitative resazurin assay to determinate the viability of Trichomonas vaginalis and the cytotoxicity of organic solvents and surfactant agents," Experimental Parasitology, vol. 123, no. 2, pp. 195-198, 2009.

[22] T. D. Rocha, P. B. Vieira, S. C. B. Gnoatto, T. Tasca, and G. Gosmann, "Anti-Trichomonas vaginalis activity of saponins from Quillaja, Passiflora, and Ilex species," Parasitology Research, vol. 110, no. 6, pp. 2551-2556, 2012.

[23] Y. Sun, H. Tong, M. Li, Y. Li, S. Guan, and J. Liu, "Immunological adjuvant effect of Japanese ginseng saponins (JGS) on specific antibody and cellular response to ovalbumin and its haemolytic activities," Vaccine, vol. 26, no. 47, pp. 5911-5917, 2008.

[24] M. I. Calvo, "Anti-inflammatory and analgesic activity of the topical preparation of Verbena officinalis L," Journal of Ethnopharmacology, vol. 107, no. 3, pp. 380-382, 2006.

[25] S.-W. Lai, M.-S. Yu, W.-H. Yuen, and R. C.-C. Chang, "Novel neuroprotective effects of the aqueous extracts from Verbena officinalis Linn," Neuropharmacology, vol. 50, no. 6, pp. 641-650, 2006.

[26] E. Speroni, R. Cervellati, S. Costa et al., "Effects of differential extraction of Verbena officinalis on rat models of inflammation, cicatrization and gastric damage," Planta Medica, vol. 73, no. 3, pp. 227-235, 2007.

[27] M. W. Biavatti, C. Farias, F. Curtius et al., "Preliminary studies on Campomanesia xanthocarpa (Berg.) and Cuphea carthagenensis (Jacq.) J.F. Macbr. aqueous extract: weight control and biochemical parameters," Journal of Ethnopharmacology, vol. 93, no. 2-3, pp. 385-389, 2004.

[28] B. E. O. Markman, E. M. Bacchi, and E. T. M. Kato, "Antiulcerogenic effects of Campomanesia xanthocarpa," Journal of Ethnopharmacology, vol. 94, no. 1, pp. 55-57, 2004.

[29] F. Calzada, L. Yépez-Mulia, and A. Tapia-Contreras, "Effect of Mexican medicinal plant used to treat trichomoniasis on Trichomonas vaginalis trophozoites," Journal of Ethnopharmacology, vol. 113, no. 2, pp. 248-251, 2007. 
[30] J. Desrivot, J. Waikedre, P. Cabalion et al., "Antiparasitic activity of some New Caledonian medicinal plants," Journal of Ethnopharmacology, vol. 112, no. 1, pp. 7-12, 2007.

[31] A. P. Frasson, O. dos Santos, M. Duarte et al., "First report of anti-Trichomonas vaginalis activity of the medicinal plant Polygala decumbens from the Brazilian semi-arid region, Caatinga," Parasitology Research, vol. 110, no. 6, pp. 2581-2587, 2012.

[32] P. B. Vieira, R. B. Giordani, G. A. de Carli, J. A. S. Zuanazzi, and T. Tasca, "Screening and bioguided fractionation of Amaryllidaceae species with anti- Trichomonas vaginalis activity," Planta Medica, vol. 77, no. 10, pp. 1054-1059, 2011. 

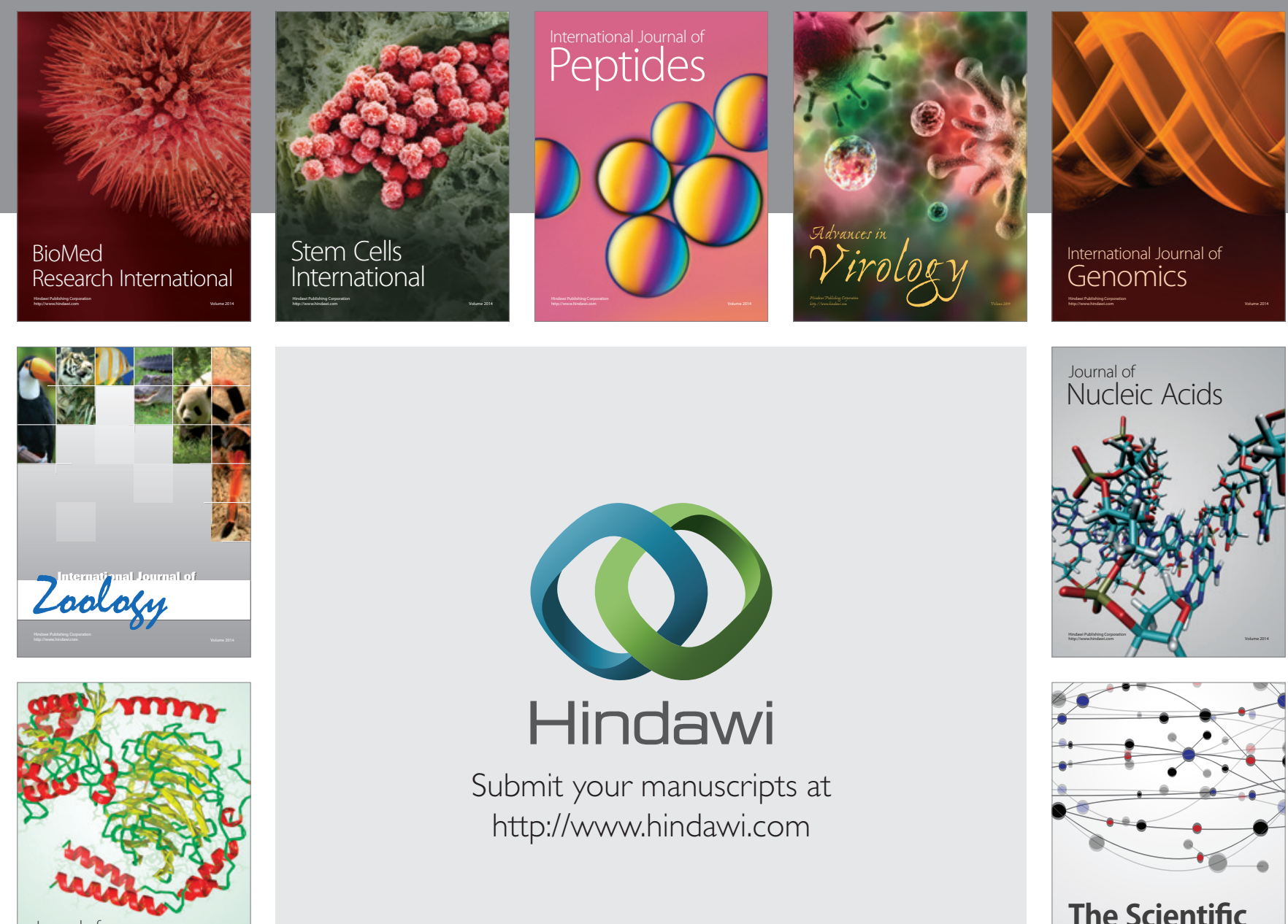

Submit your manuscripts at

http://www.hindawi.com

Journal of
Signal Transduction
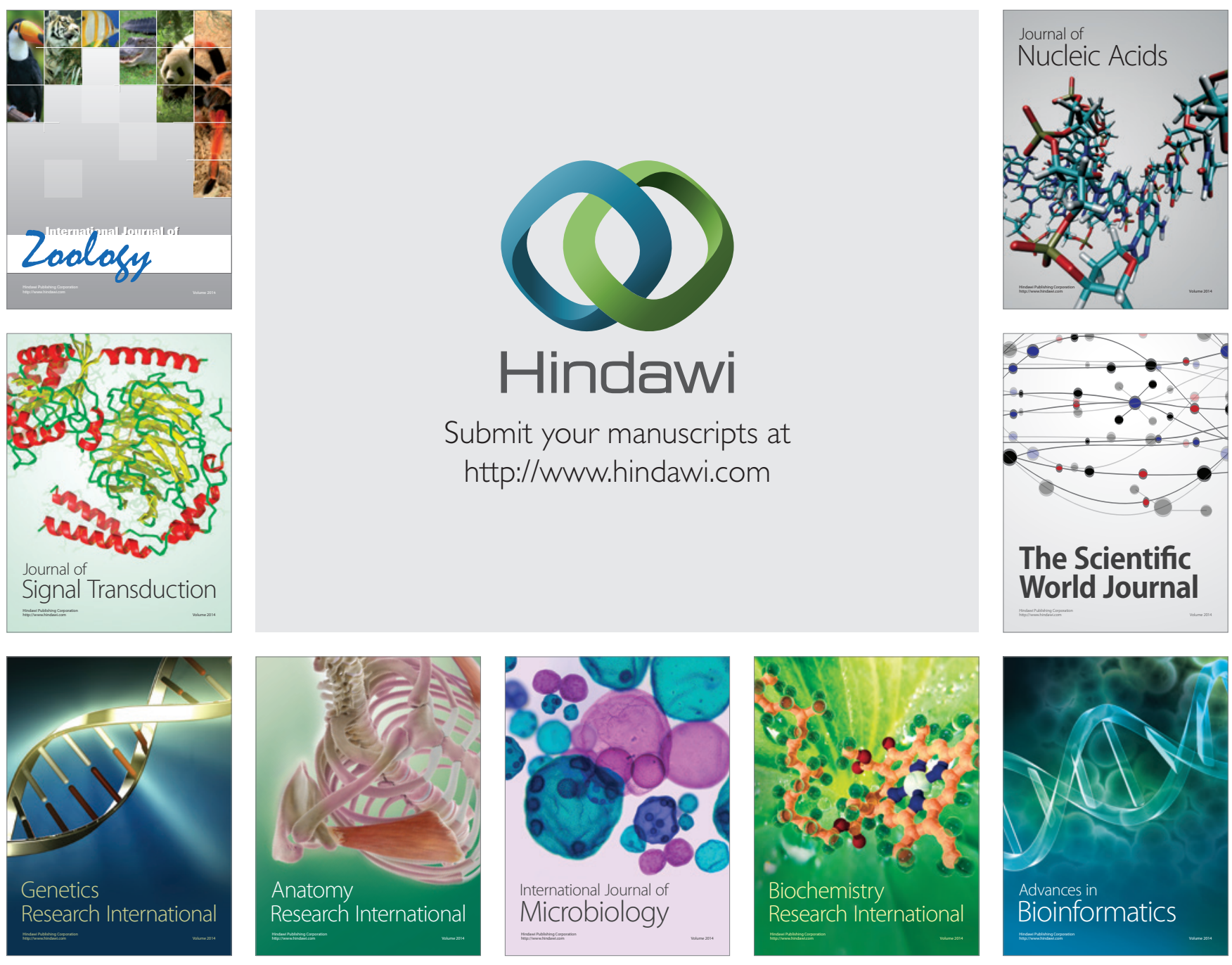

The Scientific World Journal
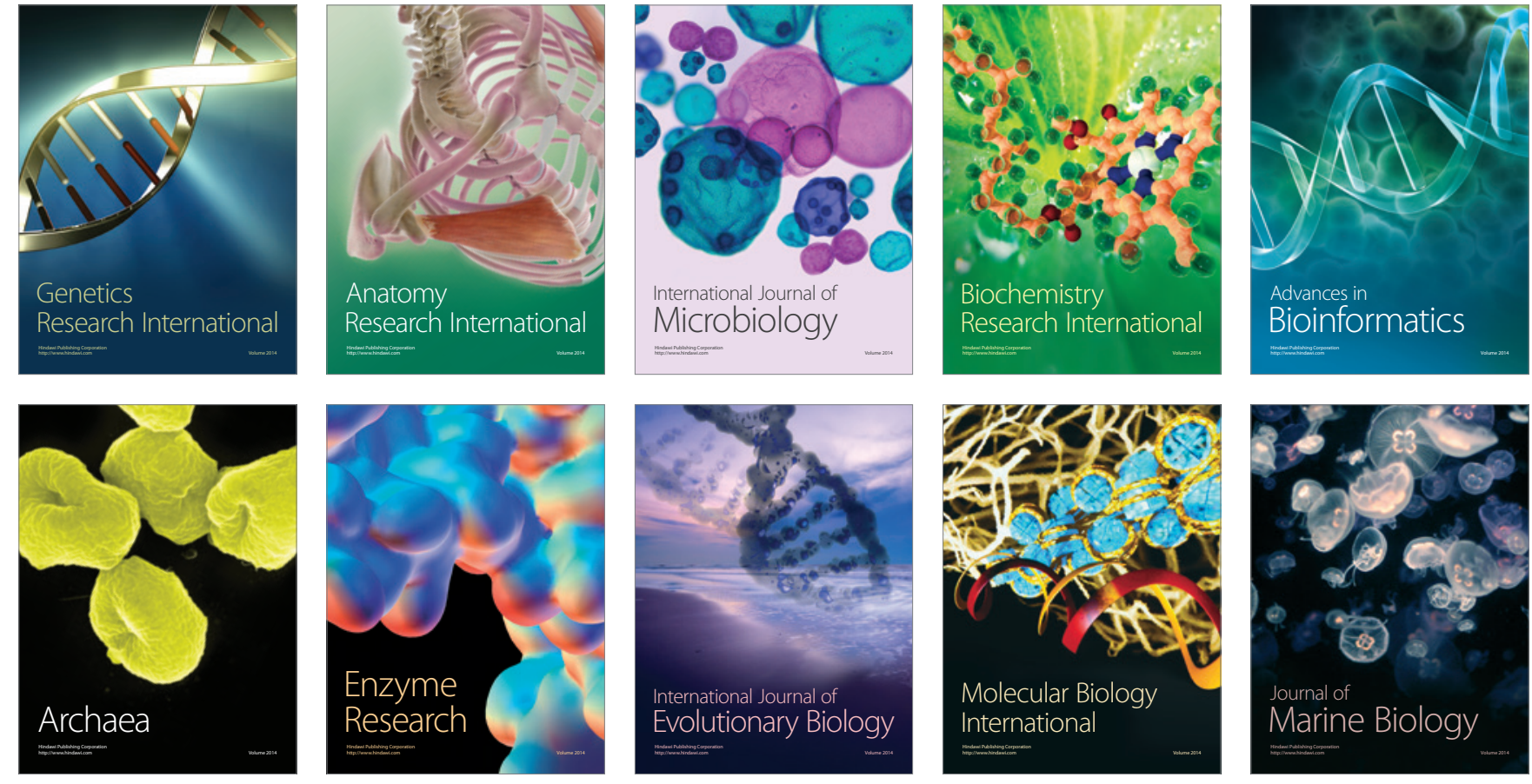